\title{
Resistance to extinction: Contingency termination and generalization decrement
}

\author{
JOHN A. NEVIN \\ University of New Hampshire, Durham, New Hampshire \\ and \\ ANTHONY P. MCLEAN and RANDOLPH C. GRACE \\ University of New Hampshire, Durham, New Hampshire \\ and University of Canterbury, Christchurch, New Zealand
}

\begin{abstract}
We present an algebraic model of resistance to extinction that is consistent with research on resistance to change. The model assumes that response strength is a power function of reinforcer rate and that extinction involves two additive, decremental processes: (1) the termination of the reinforcement contingency and (2) generalization decrement resulting from reinforcer omission. The model was supported by three experiments. In Experiment 1, 4 pigeons were trained on two-component multiple variable-interval (VI) 60-sec, VI 240-sec schedules. In two conditions, resistance to change was tested by terminating the response-reinforcer contingency and presenting response-independent reinforcers at the same rate as in training. In two further conditions, resistance to change was tested by prefeeding and by extinction. In Experiment 2, 6 pigeons were trained on two-component multiple VI 150-sec schedules with 8-sec or 2-sec reinforcers, and resistance to change was tested by terminating the response-reinforcer contingency in three conditions. In two of those conditions, brief delays were interposed between responses and response-independent reinforcers. In both Experiments 1 and 2, response rate was more resistant to change in the richer component, except for extinction in Experiment 1. In Experiment 3, 8 pigeons were trained on multiple VI 30-sec, VI 120-sec schedules. During extinction, half of the presentations of each component were accompanied by a novel stimulus to produce generalization decrement. The extinction data of Experiments 1 and 3 were well described by our model. The value of the exponent relating response strength and reinforcement was similar in all three experiments.
\end{abstract}

The construct of response strength may be identified with resistance to change when asymptotic performance is disrupted in some way (Nevin \& Grace, 2000a). One way to disrupt performance is to discontinue reinforcement, and resistance to extinction (EXT) is a traditional measure of response strength (e.g., Hull, 1943). This article describes a model of response strength and resistance to change that yields agreement between resistance to EXT and resistance to other disrupters.

Two-component multiple schedules have been used extensively in research on resistance to change of free-operant

Experiment 1 was conducted by A.P.M. and J.A.N. at the University of New Hampshire, Experiment 2 was conducted by A.P.M. at the University of Canterbury, and Experiment 3 was conducted by R.C.G. and J.A.N. at the University of New Hampshire, with support from NSF Grant IBN-9507584. A preliminary version of the present model was presented by J.A.N. and R.C.G. at the meetings of the Eastern Psychological Association in Boston, February 1998, and the data of Experiments 1 and 2 were presented at the New Zealand Behaviour Analysis Symposium, Hamilton, August 2000. Address correspondence to J. A. Nevin, RR2 Box 162, Vineyard Haven, MA 02568 (e-mail: tnevin@ worldnet.att.net), or to A. P. McLean or R. C. Grace, both at the Department of Psychology, University of Canterbury, Christchurch, New Zealand (e-mail: a.mclean@psyc.canterbury.ac.nz or r.grace@psyc. canterbury.ac.nz). behavior. In one component, signaled by a distinctive stimulus, responding is reinforced according to a schedule of intermittent reinforcement. In a second component, signaled by a different stimulus, responding is reinforced according to a separate schedule of reinforcement. Components are presented successively in regular or irregular alternation, repeatedly within sessions. After extensive training to establish stable baseline response rates in both components, a disrupter, such as prefeeding (PF), response-independent food during intercomponent intervals, or EXT, is arranged for a few sessions. Many experiments have found that when variable-interval (VI) schedules are arranged in both components, responding is less disrupted - that is, more resistant to change - in the component with the greater rate or amount of reinforcement, regardless of the asymptotic rate of responding (for a review, see Nevin, 1979, 1992). Moreover, relative resistance to change in the two components is highly correlated with preference between the stimuli signaling those components (e.g., Grace \& Nevin, 1997; Nevin $\&$ Grace, 2000b), suggesting that preference and relative resistance yield converging estimates of a construct representing the history of reinforcement correlated with a discriminative stimulus.

This construct may be identified with a masslike aspect of behavior in the metaphor of behavioral momentum 
(Nevin \& Grace, 2000a). By analogy to Newton's second law in classical mechanics, Nevin, Mandell, and Atak (1983) proposed that the change in response rate relative to baseline is directly proportional to the value of a forcelike disrupter $f$ and inversely proportional to behavioral mass $m$ :

$$
\log (B x / B o)=-f / m,
$$

where $B x$ is response rate during disruption and $B o$ is response rate during the predisruption baseline. The change in response rate is expressed as the logarithm of the proportion of baseline in order to transform equal ratios into equal differences. Moreover, a number of experiments have obtained roughly linear relations between $\log (B x / B o)$ and the value of the disrupter $f$, such as amount of PF or sessions of EXT.

Because the left side of Equation 1 is dimensionless, the units of $m$ must be the same as those of the disrupterfor example, grams of food when resistance to PF is measured. Thus, the scale of behavioral mass depends on the particulars of the disrupter, and so its generality is difficult to evaluate. To remedy this difficulty, Equation 1 may be written separately for each component. In Component 1 ,

$$
\log (B x 1 / B o 1)=-f 1 / m 1,
$$

and in Component 2,

$$
\log (B \times 2 / B o 2)=-f 2 / m 2 .
$$

Dividing Equation 2a by Equation $2 \mathrm{~b}$ gives

$$
\log (B x 1 / B o 1) / \log (B x 2 / B o 2)=(f 1 / f 2)(m 2 / m 1),
$$

in which all the ratios are dimensionless. In a review of all his research on two-component multiple schedules to that date, Nevin (1992) showed that the mass ratio approximated a power function of the ratio of baseline reinforcer rates: $m 2 / m 1=(r 2 / r 1)^{a}$. Accordingly, we will use $r^{a}$ in place of the theoretical parameter $m$ throughout the remainder of this article.

The evaluation of $a$ is not of central interest here, since $r 1$ and $r 2$ differ by a factor of 4.0 in all of the present experiments; for more effective evaluation, a number of different reinforcer ratios should be arranged. However, rearrangement of the terms of Equation 3 suggests a way to evaluate $a$ for a given pair of schedules when the disrupter is varied so as to yield a series of data points, regardless of whether the resistance data are monotonically related to the value of the disrupter:

$$
\log (B x 1 / B o 1)=(f 1 / f 2)(r 2 / r 1)^{a}[\log (B x 2 / B o 2)] .
$$

If $f 1=f 2$, the value of $a$ can be calculated from the slope $(r 2 / r 1)^{a}$ of the function relating log proportion of baseline in Component 1 to that in Component 2. Because the function relates two dependent variables, its parameters must be estimated by fitting a structural relation (Isaac, 1970).

Empirically, the requirement that $f 1=f 2$ means that the disrupter must be the same for both components, as is clearly the case for a given amount of PF before an experimental session in which the components alternate frequently at the reduced level of food deprivation. However, as we will argue below, $f 1$ does not equal $f 2$ for EXT, a frequently used disrupter in research on resistance to change and a process of long-standing theoretical interest in its own right.

Most research on resistance to change has used external disrupters, such as PF or intercomponent food, that are independent of the component schedules and are the same for both components, where the schedules in each component remain unchanged. Thus, it is reasonable to assume that $f 1=f 2$ in the momentum model. However, for EXT, the disrupter is the abrupt termination of reinforcement-an internal within-component change in the conditions of reinforcement (cf. Harper \& McLean, 1992). Moreover, the decrease in reinforcer rate from its value during training to zero is necessarily larger in the component with the greater rate of reinforcement. Thus, failures of agreement between resistance to EXT and resistance to other external disrupters (e.g., Nevin et al., 1983) may result because the change to EXT is an internal disrupter that is not the same across components differing in reinforcer rate. In relation to Equation 4, $f 1$ does not equal $f 2$, and the estimate of $a$ will be affected by this inequality.

The effects of omitting reinforcers during EXT may be interpreted in relation to the familiar process of generalization decrement, because during training, the occurrence of reinforcers was a part of the overall stimulus situation associated with responding. In a thorough review of research on generalization decrement during EXT, Mackintosh (1974) concluded that "the rate of extinction is determined by the extent to which the transfer from acquisition to extinction causes a change in the set of events associated with reinforcement ..." (p. 433). If generalization decrement is construed as a disruptive force and if its magnitude is directly related to the rate of reinforcement during training, the estimated value of $a$ may depend on the absolute rates of reinforcement in the components of a multiple schedule, as well as on their ratio.

This interpretation is confirmed by some recent data. Nevin and Grace (1999) obtained substantial agreement between relative resistance to PF and to EXT when VI schedules arranged 40 and 10 reinforcers per hour in two components. However, when the component schedules arranged 160 and 40 reinforcers per hour, responding in the $160 /$ h component was reliably more resistant to PF but was not reliably more resistant to EXT than was that in the $40 / \mathrm{h}$ component. These results suggest that differences between resistance to EXT and to other disrupters may depend on the absolute values of the component reinforcer rates during training.

The disruptive effects of EXT cannot be determined solely by generalization decrement. This is because responding generally decreases if the reinforcement contingency is terminated, as in EXT, and reinforcers are given independently of responding at the same rate as in training, so that the overall stimulus situation is unchanged. 
Rescorla and Skucy (1969) reinforced responding according to a VI 2-min schedule and then compared resistance to EXT with resistance to response-independent presentation of reinforcers (here designated $\mathrm{NC}$ for noncontingent) according to a variable-time 2-min schedule in separate groups of rats. They found that response rates decreased over sessions when response-independentfood was given, but less rapidly than when food was withheld altogether (EXT). Lattal (1972) repeated these results within subjects, and Catania and Keller (1981) showed that response rate decreases during $\mathrm{NC}$ were well described by exponential decay functions similar to those often used to describe the course of EXT (e.g., Clark, 1959). Thus, a plausible model of resistance to EXT should include separate terms for terminating reinforcement and for terminating the response-reinforcer contingency.

This approach to EXT was suggested by Catania (1973): "the discontinuation of reinforcement has two effects: A dependency between responses and reinforcers ends, and reinforcers are no longer delivered" (p. 49). He proposed that these effects could be separated by satiation, so that the dependency remains in effect while the reinforcer becomes ineffective, and by response-independent presentation of the reinforcer, as in the study by Rescorla and Skucy. Our Experiment 1 pursues this approach. But first we present an augmented model of behavioral momentum proposed by Nevin and Grace $(1999,2000$ a) that contains additive terms for contingency change and generalization decrement during EXT. The model is

$$
\log (B x / B o)=-x(c+d \Delta r) / r^{a},
$$

which is in the form of Equation 1 with the disrupter $(f)$ augmented to include sessions of EXT $x$ and additive terms representing termination of the contingency and generalization decrement owing to reinforcer omission. The parameter $c$ scales the effectiveness of terminating the operant contingency, and $d$ scales the decremental effect of situation change resulting from the change of the reinforcer rate, $\Delta r$, from $r$ in training to zero in EXT. Both $c$ and $d$ must be expressed in units that render the right side of Equation 3 dimensionless.

Rewriting Equations $2 \mathrm{a}$ and $2 \mathrm{~b}$ for two multipleschedule components, we obtain

$$
\log \left(B x_{1} / B o_{1}\right)=-x\left(c_{1}+d_{1} \Delta r_{1}\right) / r_{1}^{a}
$$

and

$$
\log \left(B x_{2} / B o_{2}\right)=-x\left(c_{2}+d_{2} \Delta r_{2}\right) / r_{2}^{a},
$$

where all terms are subscripted to indicate the appropriate multiple-schedule component. The structural relation between log proportions of baseline in Components 1 and 2 becomes

$$
\begin{aligned}
\log \left(B x_{1} / B o_{1}\right)=\left[\left(c_{1}+d_{1} \Delta r_{1}\right) /\left(c_{2}+d_{2} \Delta r_{2}\right)\right] \\
\left(r_{2} / r_{1}\right)^{a}\left[\log \left(B x_{2} / B o_{2}\right)\right] .
\end{aligned}
$$

Equations $6 \mathrm{a}, 6 \mathrm{~b}$, and 7 have five parameters to be estimated from EXT data: $a, c_{1}, c_{2}, d_{1}$, and $d_{2}$. In Experiment 1 , we attempt to reduce the number of free param- eters and estimate them independently. First, we examine the effects of terminating the response-reinforcer contingency in both components of a multiple schedule while maintaining $\mathrm{NC}$ at baseline rates $r 1$ and $r 2$. Because $\Delta r$ is zero for this procedure, Equation 7 may be rewritten as

$$
\log \left(B x_{1} / B o_{1}\right)=\left(c_{1}\right) /\left(c_{2}\right)\left(r_{2} / r_{1}\right)^{a}\left[\log \left(B x_{2} / B o_{2}\right)\right] \text {. }
$$

Second, in a separate condition, we examine resistance to PF with the baseline schedules unchanged, so that $\Delta r$ is zero as for NC. Designating the scaled disruptive effects of PF as $p$, resistance to PF is described by

$$
\log \left(B x_{1} / B o_{1}\right)=\left(p_{1}\right) /\left(p_{2}\right)\left(r_{2} / r_{1}\right)^{a}\left[\log \left(B x_{2} / B o_{2}\right)\right] \text {. }
$$

Because $\mathrm{PF}$ is an external disrupter that is applied equally to both components while the component schedules remain unchanged, $p 1=p 2$, and the slope of the structural relation is $(r 2 / r 1)^{\text {a }}$. Assuming that $a$ is constant after training to asymptote, its value should be the same when responding is disrupted by transition to NC. Therefore, if the estimated structural relation slope is the same for NC as for PF, where $p 1=p 2$ in Equation 9, we can conclude that $c 1=c 2$ in Equation 8. If confirmed, this equality implies that the effects of terminating the contingency are independent of the reinforcer rates in the components of a multiple schedule. We then ask whether the data for EXT are consistent with Equations 6a and 6b, assuming that $c 1=c 2$ and $d 1=d 2$. If the effects of contingency termination and reinforcer omission are independent and additive, the value of $c$ should be the same for NC and EXT.

\section{EXPERIMENT 1}

\section{Method}

Subjects. Four White Carneau pigeons were maintained at $85 \%$ of their free-feeding weights. They had continuous access to grit and water in their home cages, which were in a vivarium with a 12:12-h light:dark cycle. The birds had no experimental histories and were trained to keypeck by a modified autoshaping procedure.

Apparatus. The experiment was conducted in four similar threekey pigeon chambers, $35 \times 35 \times 35 \mathrm{~cm}$. The keys were $26 \mathrm{~cm}$ above the chamber floor; only the center key was used. A 28-V, 1829 bulb located $7 \mathrm{~cm}$ above the center key served as a houselight; a reflector beneath the bulb arranged diffuse illumination of the entire chamber when the houselight was on. A grain magazine was located behind a $6 \times 5 \mathrm{~cm}$ aperture $13 \mathrm{~cm}$ below the center key; the magazine was illuminated with a $28-\mathrm{V}, 1829$ bulb when grain was available. Ventilation and masking noise were provided by a blower. The experimental contingencies were arranged and data were recorded by a computer running MED-PC in an adjacent room.

Procedure. After initial keypeck training, the birds were placed directly on the final procedure, in which red and green lights were presented successively on the center key to define two multipleschedule components. Components were $60 \mathrm{sec}$ long and alternated regularly, with a 0.1 -sec timeout separating them. In one component, the key was lighted red, and food reinforcers were presented according to a VI 60-sec schedule (designated rich); in the other, the key was lighted green, and food reinforcers were presented according to a VI 240-sec schedule (designated lean). The first component of each session was chosen randomly. Sessions ended after 56 components, 28 rich and 28 lean; the houselight remained on throughout the session, except during 3 -sec reinforcer presentations.

Eight experimental conditions were conducted successively. In Conditions 1, 3, 5, and 7, designated VI Baseline, reinforcers were 
Table 1

Sequence of Conditions and Number of Sessions per Condition in Experiment 1

\begin{tabular}{llc}
\hline \multicolumn{1}{c}{ Condition } & Sessions \\
\hline 1 VI 60/h, VI 15/h & 25 \\
2 NC 60/h, NC 15/h & 25 \\
3 VI 60/h, VI 15/h & 24 \\
4 NC 60/h, NC 15/h & 23 \\
5 VI 60/h, VI 15/h & 24 \\
6 VI 60/h, VI 15/h with PF/ad lib & 32 \\
7 VI 60/h, VI 15/h & 24 \\
8 Extinction & 7 \\
\hline
\end{tabular}

Note-VI, variable interval; NC, noncontingent; PF, prefeeding.

contingent on keypecking according to the VI schedules in each component. In Conditions 2, 4, 6, and 8, the resistance to change of baseline responding was examined. In Conditions 2 and 4, designated $\mathrm{NC}(2)$ and $\mathrm{NC}(4)$, reinforcers were presented independently of responding according to variable-time schedules that were the same as the VI schedules. In Condition 6, designated PF, the baseline VI schedules were in effect, and the birds were given 20 and $40 \mathrm{~g}$ of pigeon chow in their home cages about $30 \mathrm{~min}$ before the first 2 sessions. The next 10 sessions were preceded by 60 -g PF, and for the final 20 sessions of Condition 6, the birds had ad-lib access to wheat in their home cages. After the first 3 or 4 sessions, the birds rarely ate their PF rations. Condition 7 began after their $85 \%$ weights were reestablished. In Condition 8, designated EXT, food reinforcement was discontinued altogether. The number of sessions in each condition is given in Table 1 .

\section{Results and Discussion}

Response rates in the baseline conditions were generally stable and recoverable across replications. Averaged over Conditions 1, 3, 5, and 7 for all 4 subjects, baseline response rates were 72.2 responses per minute in the rich component, which provided 60 reinforcers per hour, and 34.3 responses per minute in the lean component, which provided 15 reinforcers per hour. The difference was reliable in each of the four baseline conditions $[t(3)=5.76$, $p<.01, t(3)=4.37, p<.05, t(3)=2.69, p<.05$, and $t(3)=4.83, p<.01$, for Conditions 1, 3, 5, and 7]. The average baseline response rates in each component for the last five sessions of each condition are shown in Table 2 for individual subjects.

For each bird, daily response rates in Conditions 2 and 4 (NC), 6 (PF), and 8 (EXT) were expressed as proportions of average response rates for the last five of the immediately preceding VI VI baseline sessions and transformed to logarithms. Figure 1 presents log proportions of baseline in each schedule component, averaged across birds, for the first seven sessions of each resistance test, except for NC, in which data for Birds 177, 178, and 188 in the seventh session of Condition 4 were lost. Log proportions of baseline averaged over all resistance test sessions are given for individual subjects in Table 2.

The average data in Figure 1 show that over the course of the NC sessions, responding decreased relatively more rapidly in the lean component than in the rich component. The average decrement for all NC sessions (see Table 2) was greater in the lean component for all 4 birds in both conditions $[t(3)=8.75, p<.01$, and $t(3)=2.77, p<.05$, for NC (2) and NC (4), respectively]. The average PF data are at least qualitatively similar to those for $\mathrm{NC}$, in that responding decreased relatively more rapidly in the lean component over the first few sessions. Response rates sometimes increased after the first few PF sessions, a result that we have noted before (Nevin \& Grace, 1999). Despite these irregularities, the average decrement for all $\mathrm{PF}$ sessions was greater in the lean component for all four birds $[t(3)=3.95, p<.05]$. The average EXT data differ substantially from those for NC and PF: Responding decreased linearly over sessions with little difference between

Table 2

Baseline Response Rates for the Final Five Sessions of Conditions 1, 3, 5, and 7 and Log Proportions of Baseline Averaged Over Seven Resistance Test Sessions in Conditions 2 and 4 (NC), 6 (PF), and 8 (EXT) in Experiment 1

Responses per Minute

\begin{tabular}{|c|c|c|c|c|c|c|c|c|}
\hline \multirow[b]{2}{*}{ Bird } & \multicolumn{2}{|c|}{ Condition 1} & \multicolumn{2}{|c|}{ Condition 3} & \multicolumn{2}{|c|}{ Condition 5} & \multicolumn{2}{|c|}{ Condition 7} \\
\hline & $60 / \mathrm{h}$ & $15 / \mathrm{h}$ & $60 / \mathrm{h}$ & $15 / \mathrm{h}$ & $60 / \mathrm{h}$ & $15 / \mathrm{h}$ & $60 / \mathrm{h}$ & $15 / \mathrm{h}$ \\
\hline 177 & 93.0 & 37.3 & 77.9 & 44.5 & 77.0 & 59.0 & 79.1 & 52.1 \\
\hline 178 & 68.8 & 41.0 & 60.7 & 38.6 & 49.5 & 34.5 & 53.4 & 32.7 \\
\hline 188 & 50.2 & 21.1 & 54.7 & 15.9 & 44.2 & 12.5 & 53.1 & 11.2 \\
\hline 196 & 77.2 & 28.7 & 111.0 & 44.5 & 110.1 & 40.8 & 95.1 & 34.4 \\
\hline Mean & 72.3 & 32.0 & 76.1 & 35.9 & 70.2 & 36.7 & 70.2 & 32.6 \\
\hline
\end{tabular}

Mean Log Proportion of Baseline

\begin{tabular}{|c|c|c|c|c|c|c|c|c|}
\hline \multirow[b]{2}{*}{ Bird } & \multicolumn{2}{|c|}{ Condition 2} & \multicolumn{2}{|c|}{ Condition 4} & \multicolumn{2}{|c|}{ Condition 6} & \multicolumn{2}{|c|}{ Condition 8} \\
\hline & $60 / \mathrm{h}$ & $15 / \mathrm{h}$ & $60 / \mathrm{h}$ & $15 / \mathrm{h}$ & $60 / \mathrm{h}$ & $15 / \mathrm{h}$ & $60 / \mathrm{h}$ & $15 / \mathrm{h}$ \\
\hline 177 & -0.45 & -0.75 & -0.73 & -1.23 & 0.03 & -0.26 & -0.45 & -0.66 \\
\hline 178 & -0.17 & -0.4 & -0.49 & -0.62 & -0.22 & -0.56 & -0.45 & -0.6 \\
\hline 188 & -0.39 & -0.64 & -0.73 & -0.88 & -0.07 & -0.17 & -1.14 & -0.95 \\
\hline 196 & 0.09 & -0.09 & -0.12 & -0.31 & -0.12 & -0.28 & -1.13 & -1.24 \\
\hline Mean & -0.23 & -0.49 & -0.52 & -0.76 & -0.10 & -0.32 & -0.79 & -0.88 \\
\hline
\end{tabular}

Note-Data for the seventh session were not available for Birds 177, 178, and 188 in Condition 4. Multiple-schedule components arranged 3-sec reinforcers according to VI 60-sec $(60 / \mathrm{h})$ or VI $240-\mathrm{sec}(15 / \mathrm{h})$ schedules. 

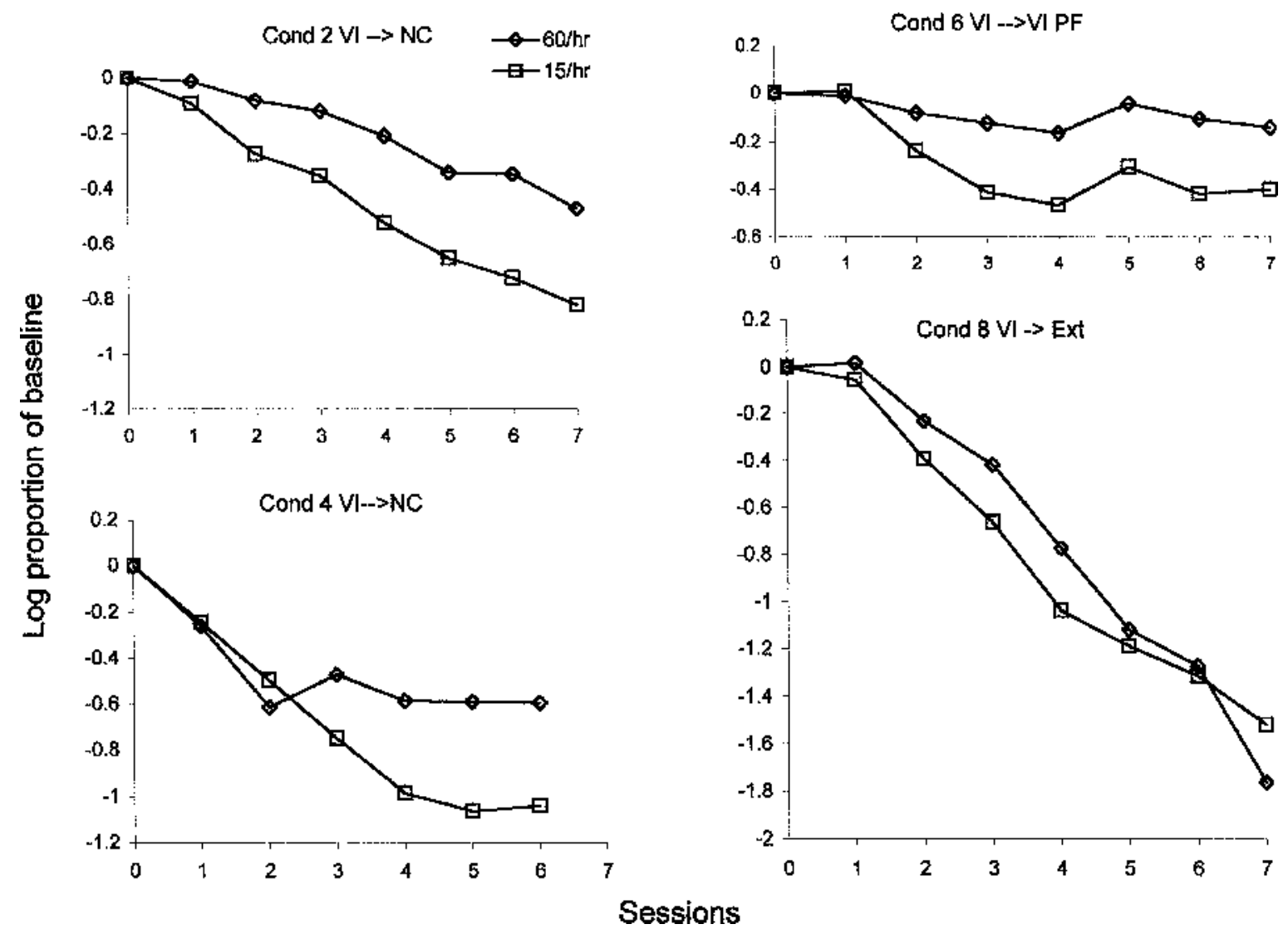

Figure 1. Mean log proportions of baseline response rates for 4 pigeons in Experiment 1 as a function of sessions for four tests of resistance to change after training on multiple variable-interval (VI) 1-min (60/h, rich), VI 4-min (15/h, lean) schedules (baseline appears as the leftmost point at 0 ). The left panels show the data for the first seven sessions following a change from response-contingent reinforcem ent to response-independent food delivered according to identical variable-time (NC) schedules in two successive conditions. On the right, the upper panel shows the data for prefeeding (PF) in the home cages before the first seven sessions, and the lower panel shows the data for all seven sessions of extinction (Ext).

components in the average rate of EXT, and the average decrements for all seven sessions did not differ consistently for individual subjects $[t(3)=0.90, p>.20]$.

Average $\log$ proportions of baseline in the lean and rich components for each of the resistance test sessions (from Figure 1) were plotted on the $x$ - and $y$-axes of Figure 2, and structural relations (Isaac, 1970) were fitted separately to the average $\mathrm{NC}, \mathrm{PF}$, and $\mathrm{EXT}$ data. If responding decreases less in the rich component, the slopes of these structural relations will be less than 1.0, and if decreases are monotonic in both components, the intercepts should be close to 0 . By inspection, the slopes are similar and substantially less than 1.0 for $\mathrm{NC}$ and $\mathrm{PF}$, implying greater resistance to change in the richer component. By contrast, the slope for EXT is about 1.0, indicating roughly equal resistance to change. Although the data are fairly noisy, their trends are captured adequately by the fitted lines.

Table 3 presents the slopes and intercepts for individual birds determined by structural-relation fits. It also gives standard errors of the slopes and intercepts and the variance accounted for by regressing response rate in the rich component on that for the lean component. The intercepts for $\mathrm{NC}$ are generally positive in $\mathrm{NC}(2)$ and uniformly negative in $\mathrm{NC}(4)$, and for EXT they are uniformly positive. Inspection of Figure 1 suggests the basis for these deviations from the expected value of zero: During the $\mathrm{NC}(4)$ test, response rate in the richer component dropped fairly rapidly during the first two sessions, whereas during EXT, response rate in the richer component exhibited an initial increase. The former effect was not replicated in Experiment 2; the latter, however, has been observed in other multiple-schedule EXT tests (e.g., Nevin \& Grace, 1999; Nevin et al., 1983).

Averaged across birds, the structural-relation slopes were similar for $\mathrm{NC}(2)$ and $\mathrm{NC}(4)$, although Bird 196 had a negative slope for $\mathrm{NC}(2)$ because its response rate increased over successive test sessions in the rich component. Within birds, there were no consistent differences between slopes for NC and PF, although Bird 177 had an unusually shallow slope for $\mathrm{PF}$ because its response rate decreased only slightly in the richer component. Mean slopes were 0.47 for $\mathrm{NC}(2), 0.49$ for $\mathrm{NC}(4)$, and 0.39 for 


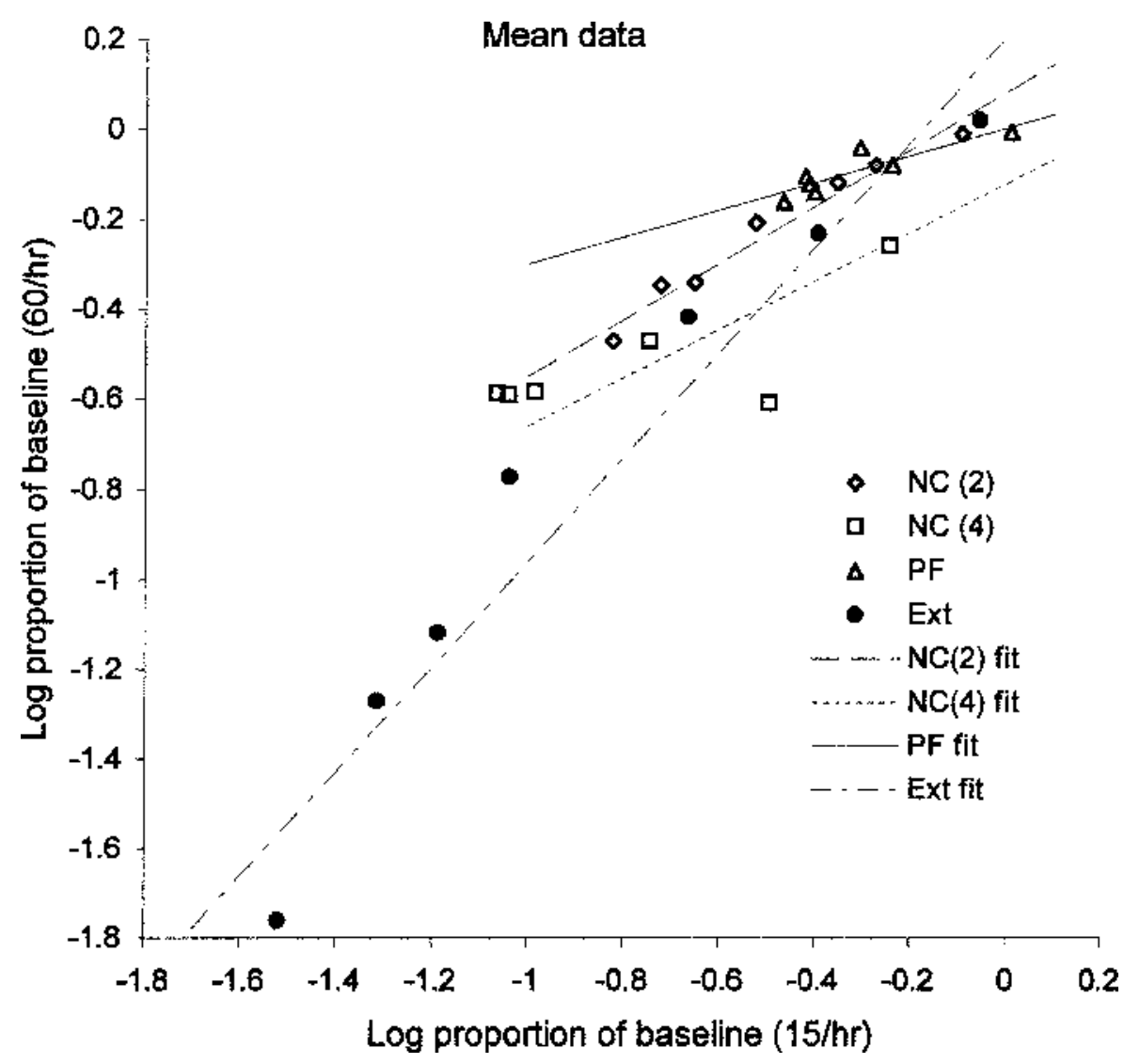

Figure 2. Structural relation plots of mean log proportions of baseline in the rich $(60 / \mathrm{h})$ component on the $y$-axis against mean log proportions of baseline in the lean $(15 / \mathrm{h})$ component on the $x$-axis for four resistance tests (data from Figure 1). The lines represent structural relations fitted to the mean data.

$\mathrm{PF}$. The means for NC and PF are reasonably similar, differing by less than the mean standard errors in these conditions. With reference to Equations 7 and 8, the absence of consistent differences between structural-relation slopes for $\mathrm{NC}$ and $\mathrm{PF}$ implies that if $p 1=p 2$ for $\mathrm{PF}$, then $c 1=c 2$ for $\mathrm{NC}$. By contrast, the structural relation slopes for EXT were substantially steeper for all the subjects $($ mean $=1.14)$. Within individuals, they differed by more than one standard error from any of the slopes for the other resistance tests. This difference implies that if the exponent relating behavioral mass to reinforcer rate (a) is the same for EXT as for NC and PF, the effective disrupter in the rich component must be greater than that in the lean component in Equations 6a and 6b.

According to the augmented model (see Equation 5), extinction is a more powerful disrupter in the rich component because $\Delta r$ is greater in that component. The argument above confirmed that contingency termination was equally effective for the two components during $\mathrm{NC}$ reinforcement (i.e., $c 1=c 2$ for $\mathrm{NC}$ ), and we assume that the same was true for contingency termination in EXT. If we know the value of $a$, we can estimate the value of $c$ in two ways. First, fitting Equations $6 \mathrm{a}$ and $6 \mathrm{~b}$ to sessionby-session $\mathrm{NC}$ data estimates $c$ in conditions with no change of reinforcer rate (i.e., $\Delta r=0$ ). Second, fitting those equations to session-by-session EXT data for both components estimates both $c$ and $d$ with $\Delta r=r 1$ or $r 2$ in Components 1 and 2. Likewise, the value of $a$ may be determined in two ways. First, as was suggested above, $a$ can be calculated from the structural-relation slopes, which averaged 0.45 for $\mathrm{NC}(2), \mathrm{NC}(4)$, and PF. If $(r 2 / r 1)^{a}=$ 0.45 , with $r 2 / r 1=0.25$, then $a=0.57$. Alternatively, the value of $a$ may be fixed at a value that is consistent across a series of experiments using closely related procedures. In both Experiments 2 and 3, the value of $a$ was found to be about 0.50 , which is similar to the obtained value of 0.57 found in Experiment 1. Accordingly, we set the value of $a$ at 0.50 . Also for consistency with Experiments 2 and 3 , we use seconds of access to food per hour in each component for $r 1$ and $r 2$. All fits were performed by a nonlinear curve-fitting program (Microsoft Excel Solver). When the $\mathrm{NC}$ data were averaged for $\mathrm{NC}(2)$ and $\mathrm{NC}(4)$, the estimated value of $c$ was 1.02. For EXT, the estimated value of $c$ was also 1.02, and the estimated value of $d$ was 
Table 3

Slopes $(m)$ and Intercepts $(b)$ of Structural Relations Fitted to the Individual Data of Experiment 1, With Least-Squares Regression Estimates of Standard Errors and Variance Accounted For (VAC)

\begin{tabular}{|c|c|c|c|c|c|c|c|c|c|c|c|c|c|c|c|c|c|c|c|c|}
\hline \multirow[b]{3}{*}{ Bird } & \multicolumn{5}{|c|}{$\mathrm{NC}(2)$} & \multicolumn{5}{|c|}{$\mathrm{NC}(4)$} & \multicolumn{5}{|c|}{ PF } & \multicolumn{5}{|c|}{ EXT } \\
\hline & \multicolumn{2}{|c|}{$m$} & \multicolumn{2}{|c|}{$b$} & \multirow[b]{2}{*}{ VAC } & \multicolumn{2}{|c|}{$m$} & \multicolumn{2}{|l|}{$b$} & \multirow[b]{2}{*}{ VAC } & \multicolumn{2}{|c|}{$m$} & \multicolumn{2}{|c|}{$b$} & \multirow[b]{2}{*}{ VAC } & \multicolumn{2}{|c|}{$m$} & \multicolumn{2}{|c|}{$b$} & \multirow[b]{2}{*}{ VAC } \\
\hline & $M$ & $S E$ & $M$ & $S E$ & & $M$ & $S E$ & $M$ & $S E$ & & $M$ & $S E$ & $M$ & $S E$ & & $M$ & $S E$ & $M$ & $S E$ & \\
\hline 177 & 0.80 & 0.23 & 0.16 & 0.13 & 0.81 & 0.43 & 0.17 & -0.20 & 0.24 & 0.41 & 0.07 & 0.20 & 0.05 & 0.07 & 0.06 & 1.05 & 0.09 & 0.24 & 0.08 & 0.96 \\
\hline 178 & 0.34 & 0.13 & -0.01 & 0.07 & 0.54 & 0.55 & 0.14 & -0.15 & 0.10 & 0.27 & 0.45 & 0.18 & 0.03 & 0.12 & 0.6 & 0.98 & 0.16 & 0.21 & 0.13 & 0.87 \\
\hline 188 & 0.85 & 0.13 & 0.15 & 0.09 & 0.88 & 0.63 & 0.08 & -0 . & $0 .($ & 0.8 & & 0.22 & 0.03 & 0.06 & 0.7 & 1.34 & 0.27 & 0.13 & 0.28 & 0.79 \\
\hline 196 & -0.11 & 0.11 & 0.09 & 0.01 & 0.14 & 0.35 & 0.08 & -0.01 & 0.03 & 0.75 & 0.41 & 0.22 & 0 & 0.10 & 0.72 & 1.17 & 0.14 & 0.32 & 0.20 & 0.92 \\
\hline Mean & 0.47 & 0.15 & 0.10 & 0.08 & & 0.49 & 0.12 & -0.14 & 0.11 & & 0.39 & 0.21 & 0.03 & 0.09 & & 1.14 & 0.17 & 0.23 & 0.17 & \\
\hline
\end{tabular}

Note-These standard errors overestimate the standard errors for structural relations because they are based on the vertical distances from the regression line to the data points, whereas the parameters of structural relations are derived from perpendiculars to the fitted line. For the same reason, regression analysis underestimates variance accounted for. NC, noncontingent; PF, prefeeding; EXT, extinction.

0.01. With these parameter values, Equations $6 \mathrm{a}$ and $6 \mathrm{~b}$ explained $99 \%$ and $98 \%$ of the variance in the $\mathrm{NC}$ and EXT data, respectively. Interestingly, these estimates of $c$ and $d$ are close to those obtained by Nevin and Grace (1999), who obtained $c=1.0$ and $d=0.009$ for a comparable range of reinforcer rates. Nevin and Grace (1999) arranged different contexts of reinforcement for different pairs of schedule components, so their model included terms for the omission of reinforcers in the overall context, as well as in the individual components. Those terms are omitted here because the context was the same for both components.

Finally, we estimated the scaled effectiveness of $\mathrm{PF}(p)$ by replacing $c$ with $p$ in Equations $6 \mathrm{a}$ and $6 \mathrm{~b}$. The fit to the PF data with $a=0.50$ gave $p=0.46$, with $99 \%$ of the variance explained.

Figure 3 shows that response rates in all sessions of all four resistance tests, expressed as log proportions of baseline, are generally well predicted by the behavioral momentum model (Equation 1) with its force term replaced by these parameter values for $c$ in $\mathrm{NC}(2)$ and $\mathrm{NC}(4), p$ in PF, and $c+d \Delta r$ in EXT, and with $m$ given by $r^{a}$ where $a=0.50$. The data for EXT tend to fall above the line of exact prediction at the upper right. The largest deviations are for the data of $\mathrm{NC}(4)$, which fall below the line, whereas the data for $\mathrm{NC}(2)$ fall slightly above the line. Because the value of $c$ was estimated for the average data of $\mathrm{NC}(2)$ and $\mathrm{NC}(4)$, the model accounted for only $87 \%$ of the variance when $\mathrm{NC}(2)$ and $\mathrm{NC}(4)$ were predicted separately.

In summary, we found that terminating the reinforcement contingency while continuing to present reinforcers (NC) led to greater reductions in response rate in the leaner component, as previously has been reported for a variety of external disrupters. The same result was obtained with PF, an external disrupter that reduced response rates while the reinforcement contingency remained in effect. In EXT, average decreases in response rates were more nearly similar in the two components, as would be expected if the omission of reinforcers had a larger decremental effect in the richer component. The full data set was well described by the behavioral momentum model of resistance to change with its disruptive force term quantified to reflect the scaled effects of contingency termination for $\mathrm{NC}$, deprivation change for $\mathrm{PF}$, and the sum of contingency termination and reinforcer omission for EXT.

\section{EXPERIMENT 2}

In Experiment 1, we argued from the similarity of slopes between $\mathrm{NC}$ and $\mathrm{PF}$ resistance tests that $c 1=c 2$ in Equation 8, implying that the effects of changing from response-contingent to $\mathrm{NC}$ reinforcement were independent of reinforcer rate. However, the effects of changing from response-contingent to $\mathrm{NC}$ reinforcement may be complicated by the fact that after the change, NC reinforcers are encountered more frequently in the component with the higher reinforcer rate, which could lead to more rapid reductions in responding in the richer component. At the same time, adventitious contiguities between responses and reinforcers would occur more often in the component with the higher reinforcer rate, which could lead to slower reductions in responding in the richer component. To control for frequency of encounter, we replicated the NC test of Experiment 1 with reinforcers that differed in magnitude but with the same reinforcer rates in the two components. Previous research has shown that differences in reinforcer magnitude between components affect resistance to change in much the same way as differences in reinforcer rates (e.g., Harper \& McLean, 1992; Nevin, 1992; Nevin, Mandell, \& Yarensky, 1981; Shettleworth \& Nevin, 1965). Also, in two further replications, we imposed brief delays between responses and $\mathrm{NC}$ food presentations for two reasons. First, such delays preclude temporal contiguities between responses and reinforcers, and second, the effectiveness of terminating the contingency (the magnitude of force in Equation 1) should be enhanced by such delays. The question is whether the greater resistance to NC in the richer com- 


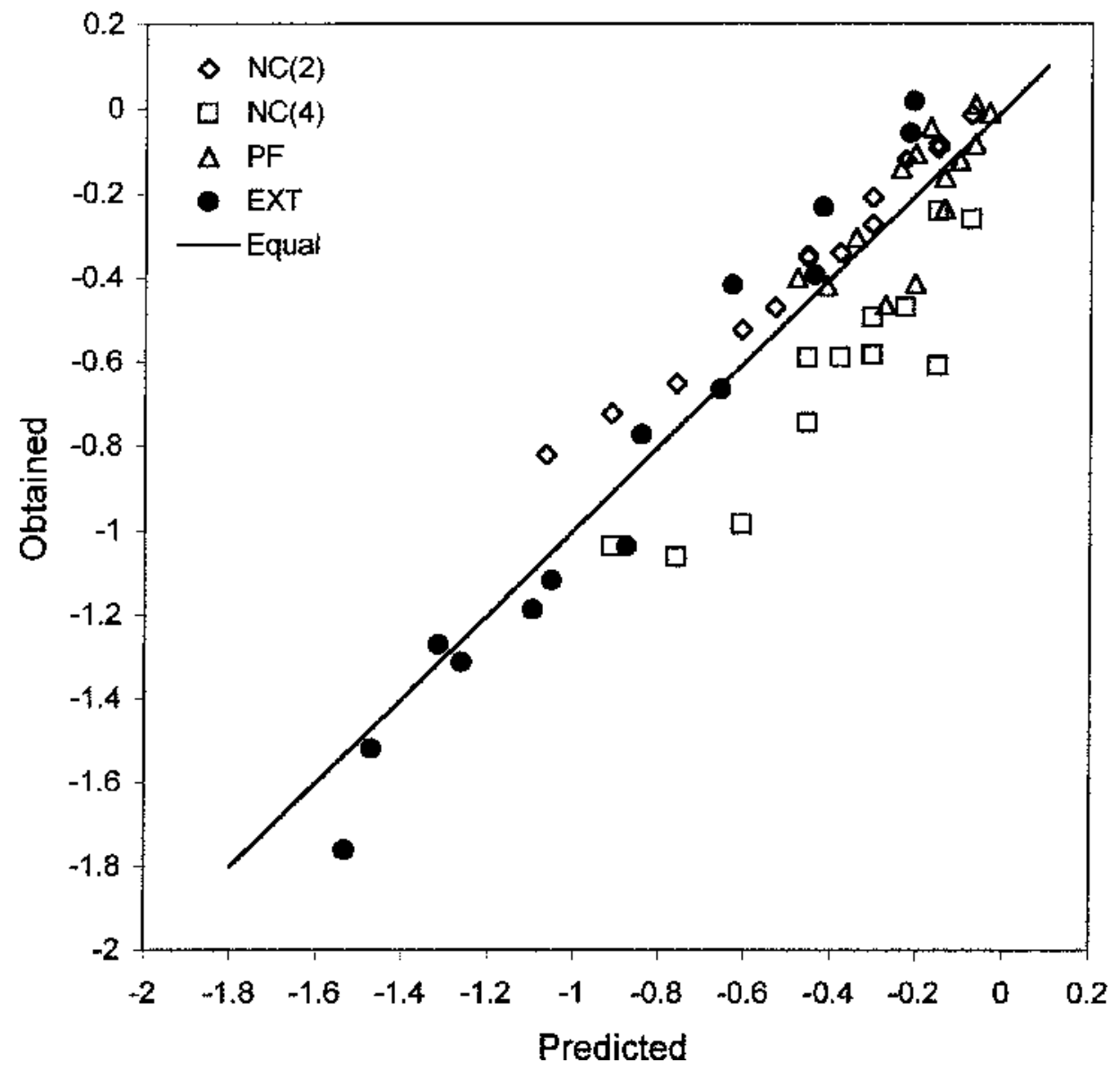

Figure 3. Obtained mean log proportions of baseline during all resistance test sessions for the rich $(60 / \mathrm{h})$ and lean $(15 / \mathrm{h})$ components (see Figure 1) plotted against values predicted by Equation 1 with its force term replaced by the scaled effects of contingency termination, prefeeding (PF), and reinforcer omission. The solid line represents exact equality of obtained and predicted values. NC, noncontingent; EXT, extinction.

ponent would be replicated with equal reinforcer rates, but unequal reinforcer magnitudes, and with progressively more effective separation of responses and reinforcers.

\section{Method}

Subjects. Six adult homing pigeons were maintained at $85 \%$ of their free-feeding weights. All 6 birds had previous experience on multiple schedules of reinforcement.

Apparatus. The experiment was conducted in six similar threekey pigeon chambers, $40 \times 40 \times 33 \mathrm{~cm}$ high. The keys were $21 \mathrm{~cm}$ above the chamber floor; only the center key was used. A houselight was located $8 \mathrm{~cm}$ above the center key, and a grain magazine was located $13 \mathrm{~cm}$ below it. Ventilation and masking noise were provided by a fan. The experimental contingencies were arranged and data were recorded by Apple IIe computers running customized BASIC software in an adjacent room.

Procedure. In view of their previous experience, the birds were placed directly on the final procedure, in which red and green lights were presented successively on the center key to define two multipleschedule components. Components were $90 \mathrm{sec}$ long and alternated irregularly, with no time-out separating them. In one component (designated rich), the key was lighted red, and 8-sec food reinforcers were presented according to a VI 150-sec schedule. In the other (designated lean), the key was lighted green, and 2-sec food reinforcers were presented according to a VI 150-sec schedule. Sessions ended after 34 components, 17 rich and 17 lean; the houselight remained on throughout the session, except during reinforcer presentations.

Six experimental conditions were conducted successively. In Conditions 1, 3, and 5, designated VI Baseline, 8- or 2-sec reinforcers were contingent on keypecking according to the VI 150-sec schedule in each component. In Condition 2, designated NC, 8- or 2 -sec reinforcers were presented independently of responding according to NC 150-sec schedules. In Condition 4, designated NC DRO2 (for differential reinforcement of other behavior), 8- or 2-sec reinforcers were arranged according to NC 150 -sec schedules, but reinforcers were not presented until $2 \mathrm{sec}$ had elapsed since the most recent keypeck. Condition 6, designated NC DRO3, was identical to Condition 4, except that $3 \mathrm{sec}$ were required to elapse since the most recent keypeck. The number of sessions in each condition is given in Table 4.

\section{Results and Discussion}

Response rates in the baseline conditions were generally stable and recoverable across replications. Averaged over all subjects for the last five sessions of all three con- 
Table 4

Sequence of Conditions and Number of Sessions per Condition in Experiment 2 Condition

1 VI 150/h, 8-sec versus 2-sec food

2 NC 150/h, 8-sec versus 2-sec food

3 VI 150/h, 8-sec versus 2 -sec food

4 NC 150/h, DRO 2-sec, 8-sec versus 2-sec food

5 VI 150/h, 8-sec versus 2 -sec food

6 NC 150/h, DRO 3-sec, 8-sec versus 2-sec food

Sessions

29

23

36

12

12

45

Note-Baseline schedules were variable-interval (VI) 150-sec (24 reinforcers/h) in both multiple-schedule components, and the duration of food access was 8 or $2 \mathrm{sec}$. NC, noncontingent; DRO, differential reinforcement of other behavior.

ditions, baseline response rates were 73.1 responses per minute in the rich component, which provided 192sec access to food per hour, and 34.1 responses per minute in the lean component, which provided 48 -sec access per hour. The difference was reliable $[t(5)=6.68, p<.01$, $t(5)=8.46, p<.01$, and $t(5)=7.15, p<.01]$ for the three successive baseline conditions. The average baseline response rates in each component for the last five sessions in each condition are shown in Table 5 for individual subjects. Note that average baseline rates in the rich and lean components were similar to those obtained in Experiment 1, which arranged 180- and 45-sec access to food per hour in the rich and lean components. Thus, the baseline data support the equivalence of reinforcer rates and durations suggested by previous multiple-schedule research (e.g., Reynolds, 1963; Shettleworth \& Nevin, 1965).

For each bird, daily response rates in Conditions 2 (NC), 4 (NC DRO2), and 6 (NC DRO3) were expressed as proportions of average response rates for the last five of the immediately preceding baseline sessions and transformed to logarithms. Figure 4 presents $\log$ proportions of baseline in each schedule component, averaged across birds, for the first seven sessions. As is shown in the upper panel, the transition to $\mathrm{NC}$ had a greater decremental effect on responding in the lean component, as in both NC conditions of Experiment 1. Subsequent transitions with 2- or 3-sec delays between a keypeck and food presentation produced progressively steeper decremental functions for all birds.

Table 5 shows that for every bird in every condition, the average decrement in log proportion of baseline over all seven resistance test sessions was greater in the component with the smaller reinforcer. In addition, the average decrement increased systematically with the value of the delay imposed before reinforcer presentation. An analysis of variance showed that the main effects of the DRO condition $[F(2,10)=19.82, p<.001]$ and reinforcer magnitude $[F(1,5)=33.33, p<.01]$ were significant. The interaction of DRO and magnitude was not significant. Also, a linear contrast for trend was significant $[F(1,5)=$ $37.46, p<.01$ ], showing that resistance decreased from $\mathrm{NC}$ to NC DRO2 to NC DRO3. We conclude that resistance to terminating the contingency is greater in the richer component when reinforcers differ in duration, as well as when they differ in rate, as in Experiment 1, and that this difference holds when brief delays are interposed between responses and reinforcers.

Slopes and intercepts of structural relations for individual subjects in each condition are given in Table 6. Averaged across subjects, slopes were $0.51,0.52$, and 0.53 in the three conditions, and intercepts did not differ consistently from 0.0 . Figure 5 shows the relation between average log proportions of baseline in the two components. The data for all three conditions are adequately described by a line with an intercept of 0.0 and a slope of 0.50 , which is similar to 0.48 , the mean structural relation slope for NC in Experiment 1 (see Table 3). Thus, the structural relation slope is essentially the same when component reinforcer rates and magnitudes differ by the same ratio and when the effectiveness of terminating the contingency is increased by imposing brief delays between responses and reinforcers.

We used Microsoft Excel Solver to obtain separate estimates of the values of $c$ for each of the three conditions by least-squares fits of $\log (B x / B o)=-x c / r^{a}$ to the average data for both components for each session in all three conditions, with $a$ set at 0.50, as in Experiment 1 (note that this is identical to the value implied by a structural-relation slope of 0.50 with $r 2 / r 1=0.25$ ). Thus, each value of $c$ was estimated from 14 data points. The estimated values of $c$ were $0.32,0.77$, and 1.20 for the $\mathrm{NC}, \mathrm{NC} \mathrm{DRO} 2$, and NC DRO3 conditions, respectively. In all, the fitted values accounted for $92 \%$ of the variance. Although the value of $a$ was the same as that used for estimating $c$ for the NC

Table 5

Baseline Response Rates in Responses per Minute for the Final Five Sessions of Conditions 1, 3, and 5 and Average Log Proportions of Baseline for the First Seven

Sessions of Conditions 2 (NC), 4 (NC DRO $2 \mathrm{sec}$ ), and 6 (NC DRO 3 sec), for Individual Subjects in Experiment 2

\begin{tabular}{|c|c|c|c|c|c|c|}
\hline \multirow[b]{3}{*}{ Bird } & \multicolumn{6}{|c|}{ Responses per Minute } \\
\hline & \multicolumn{2}{|c|}{ Condition 1} & \multicolumn{2}{|c|}{ Condition 3} & \multicolumn{2}{|c|}{ Condition 5} \\
\hline & 8 -sec & 2-sec & 8-sec & $2-\mathrm{sec}$ & 8 -sec & 2-sec \\
\hline P1 & 63.7 & 21.5 & 80.3 & 26.1 & 79.0 & 17.3 \\
\hline P2 & 80.8 & 33.8 & 69.0 & 23.9 & 64.7 & 21.6 \\
\hline P3 & 60.0 & 31.2 & 62.1 & 29.4 & 54.2 & 20.2 \\
\hline $\mathrm{P} 4$ & 107.4 & 53.1 & 94.9 & 49.0 & 72.1 & 39.5 \\
\hline P5 & 77.7 & 57.2 & 99.1 & 59.3 & 105.1 & 55.7 \\
\hline P6 & 51.8 & 26.0 & 49.2 & 27.8 & 44.4 & 22.0 \\
\hline Mean & 73.6 & 37.1 & 75.8 & 35.9 & 69.9 & 29.4 \\
\hline
\end{tabular}

Mean Log Proportion of Baseline

\begin{tabular}{|c|c|c|c|c|c|c|}
\hline \multirow[b]{2}{*}{ Bird } & \multicolumn{2}{|c|}{ Condition 2} & \multicolumn{2}{|c|}{ Condition 4} & \multicolumn{2}{|c|}{ Condition 6} \\
\hline & 8 -sec & 2-sec & 8 -sec & 2-sec & 8 -sec & 2-sec \\
\hline $\mathrm{P} 1$ & -.011 & -.225 & -.268 & -.632 & -.268 & -.499 \\
\hline P2 & -.092 & -.364 & -.175 & -.587 & -.366 & -.687 \\
\hline P3 & -.001 & -.060 & -.122 & -.174 & -.176 & -.342 \\
\hline $\mathrm{P} 4$ & -.078 & -.139 & -.330 & -.544 & -.422 & -.605 \\
\hline P5 & -.148 & -.223 & -.363 & -.475 & -.378 & -1.054 \\
\hline P6 & -.058 & -.295 & -.166 & -.467 & -.519 & -1.073 \\
\hline Mean & -.064 & -.218 & -.237 & -.480 & -.355 & -.710 \\
\hline
\end{tabular}

Note-Multiple-schedule components arranged 8-sec or 2-sec reinforcers according to VI 150-sec schedules. 

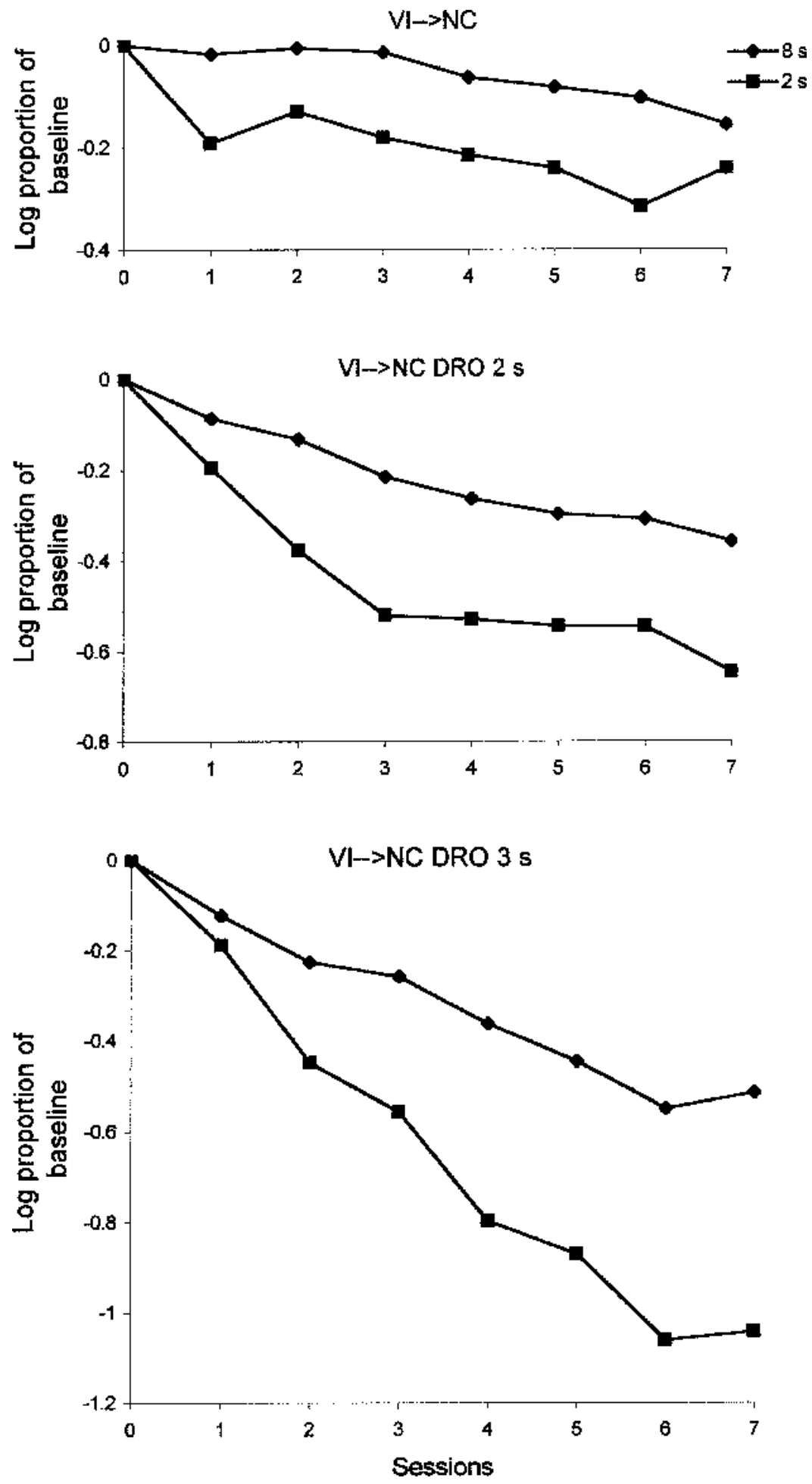

Figure 4. Mean log proportions of baseline response rates for 6 pigeons in Experiment 2 as a function of sessions for three tests of resistance to change after training on multiple variable-interval (VI) 150-sec schedules with 8-sec (rich) or 2-sec (lean) reinforcer durations to response-independent food (baseline appears as the leftmost point at 0 ). The top panel presents data for transitions to noncontingent $(\mathrm{NC})$; the middle panel presents data for transitions to $\mathrm{NC}$ with a 2 -sec delay (DRO $2 \mathrm{sec}$ ) imposed between responses and food presentation; and the bottom panel presents data for a 3 -sec delay (DRO $3 \mathrm{sec}$ ). 
Table 6

Slopes $(m)$ and Intercepts $(b)$ of Structural Relations Fitted to the Individual Data of Experiment 2, With Standard Errors and Variance Accounted for (VAC) Estimated by Regression Analyses

\begin{tabular}{|c|c|c|c|c|c|c|c|c|c|c|c|c|c|c|c|}
\hline \multirow[b]{3}{*}{ Bird } & \multicolumn{5}{|c|}{$\mathrm{NC}$} & \multicolumn{5}{|c|}{ NC (DRO2) } & \multicolumn{5}{|c|}{ NC (DRO3) } \\
\hline & \multicolumn{2}{|c|}{$m$} & \multicolumn{2}{|c|}{$b$} & \multirow[b]{2}{*}{ VAC } & \multicolumn{2}{|c|}{$m$} & \multicolumn{2}{|c|}{$b$} & \multirow[b]{2}{*}{ VAC } & \multicolumn{2}{|c|}{$m$} & \multicolumn{2}{|c|}{$b$} & \multirow[b]{2}{*}{ VAC } \\
\hline & $M$ & $S E$ & $M$ & $S E$ & & $M$ & $S E$ & $M$ & $S E$ & & $M$ & $S E$ & $M$ & $S E$ & \\
\hline$\overline{\mathrm{P} 1}$ & 0.40 & 0.16 & 0.08 & 0.04 & 0.49 & 0.34 & 0.23 & -0.05 & 0.15 & 0.19 & 0.67 & 0.13 & 0.07 & 0.07 & $\overline{0.83}$ \\
\hline $\mathrm{P} 2$ & -0.03 & 0.15 & -0.10 & 0.06 & 0.01 & 0.18 & 0.11 & -0.07 & 0.07 & 0.33 & 0.76 & 0.18 & 0.16 & 0.13 & 0.75 \\
\hline P3 & 0.39 & 0.31 & 0.02 & 0.02 & 0.09 & 0.95 & 0.38 & 0.04 & 0.07 & 0.25 & 0.62 & 0.17 & 0.04 & 0.06 & 0.67 \\
\hline $\mathrm{P} 4$ & 1.34 & 0.47 & 0.10 & 0.07 & 0.12 & 0.71 & 0.10 & 0.06 & 0.06 & 0.91 & 0.60 & 0.13 & -0.06 & 0.08 & 0.80 \\
\hline P5 & 0.84 & 0.38 & 0.04 & 0.11 & 0.17 & 0.87 & 0.29 & 0.05 & 0.14 & 0.49 & 0.36 & 0.04 & 0.01 & 0.05 & 0.95 \\
\hline P6 & 0.09 & 0.16 & -0.03 & 0.05 & 0.04 & 0.06 & 0.12 & -0.13 & 0.06 & 0.04 & 0.19 & 0.07 & -0.32 & 0.08 & 0.62 \\
\hline Mean & 0.51 & & 0.02 & & & 0.52 & & -0.02 & & & 0.53 & & -0.02 & & \\
\hline
\end{tabular}

Note-These standard errors overestimate the standard errors for structural relations because they are based on the vertical distances from the regression line to the data points, whereas the parameters of structural relations are derived from perpendiculars to the fitted line. For the same reason, regression analysis underestimates VAC.

conditions in Experiment 1, the value of $c$ was substantially lower in Experiment 2. In summary, the results of Experiments 1 and 2 suggest that the scaled effect of suspending the contingency is equal in both rich and lean components, regardless of whether the components differ in reinforcer rate or magnitude.

\section{EXPERIMENT 3}

Our model of resistance to EXT interprets the effect of omitting reinforcers as generalization decrement, and its expression in Equation 5 assumes that this effect is additive with the effect of terminating the operant contingency. There is no direct way to test this assumption in EXT, because when reinforcers are never presented, the reinforcement contingency is necessarily undefined. However, the plausibility of this assumption may be tested by presenting a novel stimulus during EXT to produce generalization decrement experimentally, rather than by inference, and ascertaining whether the effects of the novel stimulus are additive with those of terminating reinforcement. Accordingly, after training on a multiple schedule with rich and lean components, we added a novel flashing houselight to half of the presentations of each component during EXT. Presenting a novel flashing light, an external disrupter that is the same for rich and lean components, is not operationally the same as omitting intermittent food, an internal disrupter that differs between components. However, it should be functionally equivalent with respect to the process of generalization decrement.

To bring our model to bear on this situation, Equation 5 was modified to include a term for explicit stimulus change:

$$
\log (B x / B o)=-x\left(c+d \Delta r+d_{f}\right) / r^{a},
$$

where $d_{f}$ represents the scaled decremental effect of the novel flashing houselight, which is independent of the

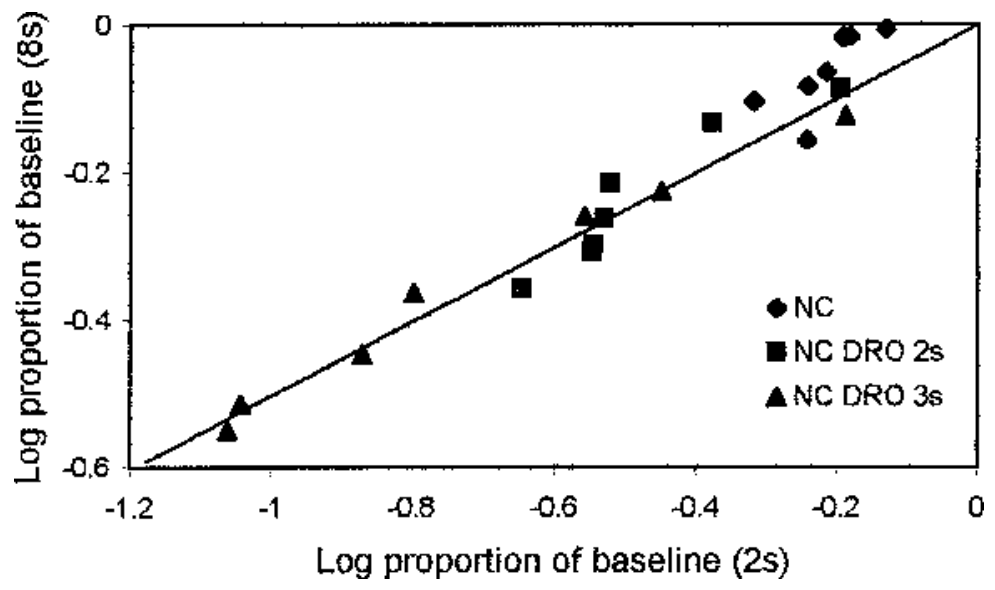

Figure 5. Structural relation plots of mean $\log$ proportions of baseline in the rich $(8$ sec) component on the $y$-axis against mean log proportions of baseline in the lean $(2 \mathrm{sec})$ component on the $x$-axis for three resistance tests (data from Figure 4). The solid line has a slope of 0.5 . NC, noncontingent; DRO, differential reinforcement of other behavior. 
Table 7

Baseline Response Rates in the Variable-Interval (VI) 30-sec (Rich) and VI 120-sec (Lean) Components and Average Log Proportion of Baseline for the First Four Blocks of Extinction in the Rich and Lean Components, With and Without the Addition of a Flashing Houselight, for Individual Subjects in Experiment 3

\begin{tabular}{lrrrrrrr}
\hline & \multicolumn{2}{c}{ Baseline } & & \multicolumn{4}{c}{ Log Proportion of Baseline } \\
\cline { 2 - 3 } \cline { 5 - 7 } Bird & Rich & Lean & & Rich & Lean & Rich $+\mathrm{F}$ & Lean $+\mathrm{F}$ \\
\hline 028 & 95.6 & 55.9 & & -0.083 & -0.070 & -0.110 & -0.235 \\
029 & 62.6 & 41.6 & & -0.669 & -0.864 & -0.904 & -1.224 \\
030 & 49.1 & 29.0 & & -1.119 & -0.885 & -1.386 & -1.480 \\
032 & 163.0 & 47.2 & & -0.772 & -0.754 & -1.000 & -1.301 \\
181 & 100.0 & 62.4 & & -0.337 & -0.519 & -0.687 & -0.913 \\
186 & 118.0 & 68.3 & & -0.551 & -0.941 & -1.543 & -1.959 \\
187 & 30.4 & 49.5 & & -0.577 & -0.796 & -0.656 & -0.864 \\
195 & 55.9 & 53.9 & -1.408 & -0.914 & -1.903 & -1.426 \\
Mean & 84.3 & 50.0 & -0.693 & -0.718 & -1.024 & -1.175 \\
\hline
\end{tabular}

baseline schedule in a component (clearly, $d_{f}$ is zero for components not accompanied by flash). Because $d_{f}$ is a larger proportion of the term in parentheses for the lean component, and because $r^{a}$ is smaller in that component, Equation 10 predicts that the decremental effect of the added houselight will be relatively greater in the lean than in the rich component.

\section{Method}

Subjects. Eight White Carneau pigeons were maintained at $85 \%$ of their free-feeding weights. They had continuous access to grit and water in their home cages, which were in a vivarium with a 12:12-h light:dark cycle. The experiment was conducted in two replications with 4 birds each. Birds $28,29,30$, and 32 had previous experimental histories with multiple and concurrent-chains schedules; Birds 181, 186, 187, and 195 had experimental histories with multiple schedules.

Apparatus. The experiment was conducted in the four three-key pigeon chambers employed in Experiment 1. Only the two side keys were used.

Procedure. In view of their experimental histories, all the subjects were exposed directly to a two-component multiple schedule with VI 30-sec (designated rich) and VI 120-sec (designated lean) schedules signaled by lighting the left key red or the right key green in irregular alternation. Reinforcement consisted of 3-sec access to wheat. The assignment of rich and lean schedules to key color and location was counterbalanced across birds. Component duration was $30 \mathrm{sec}$, and components were separated by a 10-sec time-out during which both keys were dark. Sessions ended after 90 components, 45 rich and 45 lean; the houselight remained on throughout the session, except during 3-sec reinforcer presentations.

After 44 sessions of baseline training, a single EXT session was conducted in which red and green lights alternated irregularly on the left and right keys, as in training. A randomly chosen half of the presentations of each color was accompanied by a flashing houselight ( $0.25 \mathrm{sec}$ on, $0.25 \mathrm{sec}$ off $)$ as a novel stimulus designed to produce generalization decrement. Except for those presentations, the houselight was on throughout the remainder of the session, which ended when no pecks had occurred for at least 10 successive presentations of each component.

\section{Results and Discussion}

Over the last five training sessions, baseline response rates averaged 84.3 responses per minute in the rich component and 50.0 responses per minute in the lean component. Baseline response rates were greater in the rich component for 7 of 8 birds [ $t(7)=2.45, p<.05$; see Table 7].

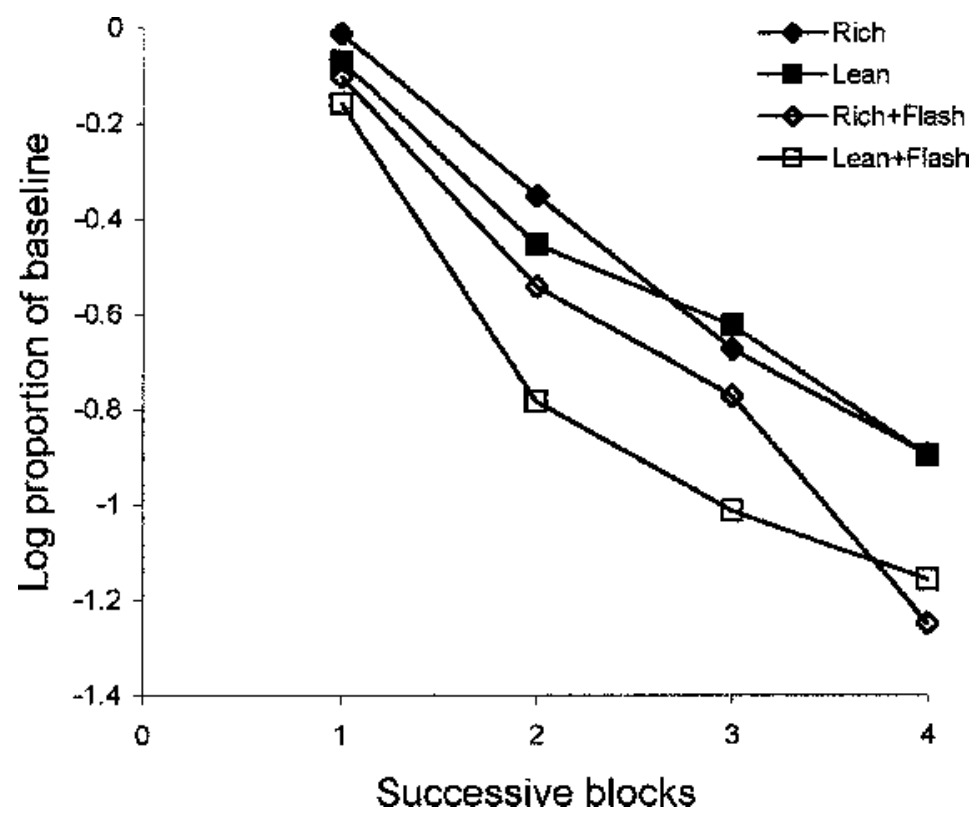

Figure 6. Mean log proportions of baseline response rates for 8 pigeons over four blocks of extinction following training on multiple variable-interval (VI) 30-sec (rich), VI 120-sec (lean) schedules in Experiment 3. During extinction, a random half of the presentations of each component stimulus was accompanied by a novel flashing houselight (rich + flash, lean + flash). 


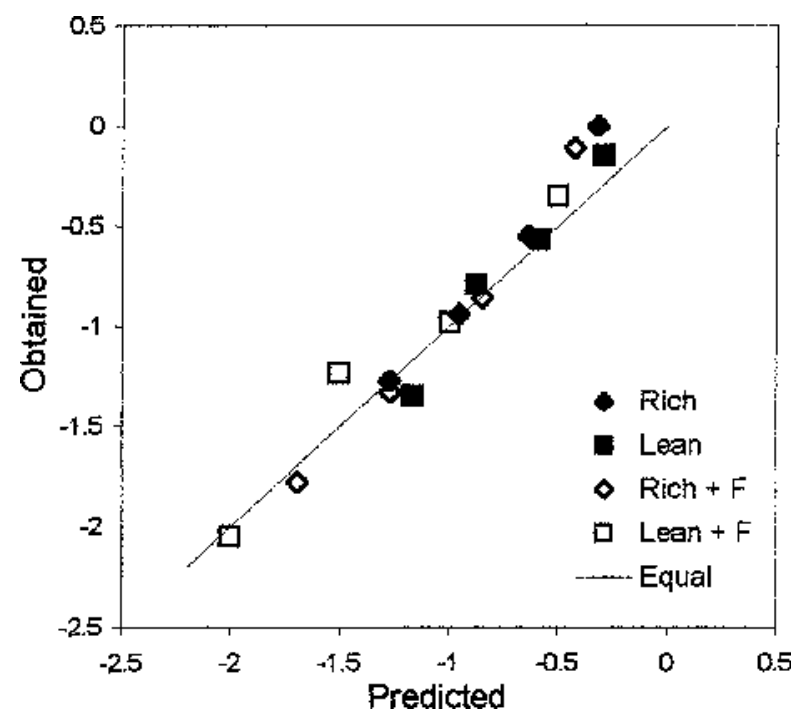

Figure 7. Obtained mean log proportions of baseline during four blocks of extinction (see Figure 6) plotted against values predicted by Equation 10 for the rich and lean components, with and without a novel flashing houselight $(F)$. The solid line represents exact equality of obtained and predicted values.

EXT test sessions lasted from 2.5 to $7.5 \mathrm{~h}$ for different subjects before the EXT criterion was met. Accordingly, individual sessions were blocked into fifths of total session length, and response rates were calculated for each block. As in Experiments 1 and 2, these response rates were then expressed as log proportions of baseline and averaged across subjects. Figure 6 shows the average data for the first four blocks; the fifth is omitted because it contained few if any responses in one or more components.

By inspection of Figure 6, there was little difference in the rates of EXT in the rich and lean components, but the EXT functions are steeper for components accompanied by the flashing houselight, with some suggestion that the flash had a greater decremental effect in the lean component. The average relative decrement in responding over all four blocks was greater in components accompanied by the flash in 16 of 16 comparisons (see Table 6 ). In addition, the decrement in log proportion of baseline produced by the added flash was greater in the lean component for 6 of the 8 birds. A repeated measures analysis of variance found a significant effect of the added flash $[F(1,7)=14.51, p<.01]$ and a significant interaction of the added flash and component reinforcer rate $[F(1,7)=$ $6.78, p<.05]$. The latter result shows that the flash had a greater decremental effect in the leaner component. However, the main effect of component reinforcer rate was not significant.

To evaluate the predictive adequacy of Equation 10, we used Microsoft Excel Solver to estimate its parameters by fitting it to the average data shown in Figure 6 with $a=0.50$, a value that described the data of both Experi- ments 1 and 2 . Thus, three free parameters were estimated from 16 data points. The fit yielded $c=1.67, d=0.012$, and $d f=1.98$, with $90 \%$ of the variance accounted for. The values of $c$ and $d$ are close to those determined in Experiment 1. As is shown in Figure 7, obtained log proportions of baseline at the upper right were slightly but consistently greater than was predicted, as was also true of the EXT data in Figure 3. Nevertheless, the model describes the overall trends in the data well. We conclude that experimentally arranged generalization decrement affects responding during EXT in a manner that is similar to generalization decrement owing to reinforcer omission assumed in the model (Equation 10).

\section{GENERAL DISCUSSION}

We have proposed a model of resistance to EXT that assumes that response rate decreases reflect the additive effects of two disrupters. The first is termination of the reinforcement contingency. Experiment 1 showed that terminating the contingency in both components of a multiple schedule by shifting from VI to NC reinforcement had a greater decremental effect on response rate in the leaner component. Experiment 1 also showed that the effects of terminating the contingency agreed closely with the effects of PF with the baseline contingencies unchanged, in that the relations between log proportions of baseline in the rich and the lean components were similar in slope. This agreement suggested that the scaled effect of changing the contingency was independent of the reinforcer rate in a component, despite the possibilities that the change in contingency might be detected earlier in the richer component and that adventitious reinforcement was likelier in the richer component. Experiment 2 replicated the effects of terminating the contingency when components differed in reinforcer magnitudes rather than rates, both without and with brief delays interposed between responses and reinforcers to preclude adventitious reinforcement. The relations between $\log$ proportions of baseline in the rich and the lean components were similar in slope across conditions with and without interposed delays and were similar to the slope obtained when the contingency was terminated in Experiment 1 . The results were consistent with equivalence in the effects of relative reinforcer rate and magnitude on relative behavioral mass (e.g., Nevin et al., 1981). More specifically, the exponent of the power function relating mass ratios to reinforcer ratios was about 0.5 in both experiments.

The second disrupter in EXT is interpreted as generalization decrement arising from the omission of reinforcers, which is directly related to reinforcer rate. The session-bysession within-component EXT data of Experiment 1 were well predicted by the addition of a parameter characterizing the effectiveness of reinforcer omission. Experiment 3 showed that response rate decreased more rapidly when generalization decrement was produced by adding an explicit novel stimulus during EXT, in the 

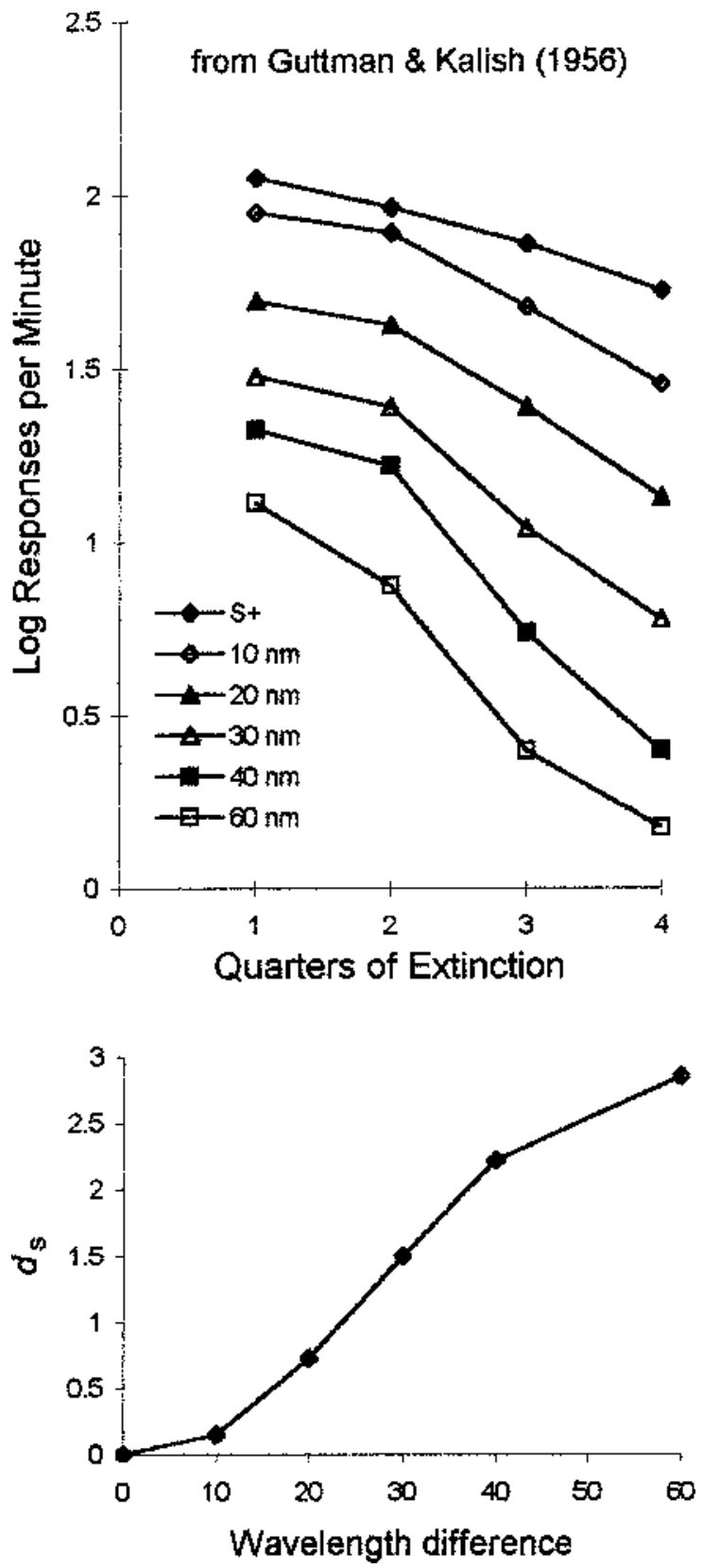

Figure 8. The upper panel presents mean log response rates during successive quarters of wavelength generalization testing in extinction, replotted from Guttman and Kalish (1956). The legend gives the difference between training and test wavelengths. The lower panel shows the estimated value of $d_{s}$ in Equation 10 as a function of the difference between training and test wavelengths.

same way as that predicted by generalization decrement resulting from reinforcer omission. The data were well described by our model with parameter values similar to those in Experiments 1 and 2, with the addition of a parameter representing the disruptive effects of the novel stimulus. Thus, these three experiments support our model.
All three of the experiments reported here used a 4:1 ratio of reinforcer rates or magnitudes, with absolute values that covered a fairly narrow range. Further evaluation of our model should arrange a substantially wider range of reinforcer rates in multiple-schedule components in order to evaluate the exponent $a$ more effectively and to ascertain whether the parameter $d$, which scales generalization decrement owing to reinforcer omission, is invariant with respect to reinforcer rate.

There are some aspects of our model that may not be directly testable with EXT data. For example, it is not possible to vary the degree of contingency change in EXT, because there are no response-contingent events. Therefore, the assumed additivity of the effects of discontinuing the contingency and omitting reinforcers must be tested in factorial studies of resistance to change that vary the degree of response-reinforcer contingency with reinforcer rate constant and vary the reinforcer rate with the contingency constant. In a relevant study, Harper and McLean (1992) examined variations in reinforcer rate with the contingency constant. They arranged multiple VI VI schedules with thirty 6-sec reinforcers per hour in one component and thirty 2 -sec reinforcers in the other component. After training to asymptote, they increased reinforcer rate to $60 / \mathrm{h}$ in both components with reinforcer magnitudes as in baseline. Equation 5 (which we repeat for convenience) makes a clear prediction for this situation, with the sign changed to reflect the fact that response rates increased relative to baseline:

$$
\log (B x / B o)=x(c+d \Delta r) / r^{a} .
$$

The change in reinforcement is the difference between $30 / \mathrm{h}$ and $60 / \mathrm{h}$ conditions expressed in seconds of access to food per hour. The contingency-change parameter $c$ may be assumed to be 0.0 , because the responsereinforcer contingencies characteristic of VI schedules remain unchanged. If $a$ is less than 1.0, Equation 8 predicts that response rate will change more rapidly in the large-magnitude component because $\Delta r$ is larger in that component. Harper and McLean did not find any consistent differences in the rates of increase in response rates during the first few sessions after the change in reinforcer rates, a result that could be explained by assuming that $a=1.0$ or by allowing $c$ to take a nonzero value. The issue of how to combine the effects of the contingency and the reinforcer rate can be addressed via further experiments that change the reinforcer rate to values other than zero.

\section{Extension to Stimulus Generalization}

Although Equation 5 describes the effects of a singlevalued novel stimulus, it may also be applied to gradients of stimulus generalization where the difference between a novel test stimulus and the training stimulus varies along a continuum during extinction. Figure 8 (upper panel) presents the average wavelength generalization gradients reported by Guttman and Kalish (1956), replotted to show how response rate (transformed to loga- 
rithms) changed over successive quarters of the generalization test, with the difference between the training wavelength and the testing wavelengths as a parameter. The functions become lower and steeper as the wavelength difference increases.

To model the Guttman and Kalish (1956) data, we identified $B o$ with response rate to $\mathrm{S}+$ in the first quarter of EXT, and interpreted $d_{f}$ (renamed $d_{s}$ ) as representing the decremental effects of wavelength difference in a version of Equation 10:

$$
\log (B x / B o)=-x\left(c+d \Delta r+d_{s}\right) / r_{a} .
$$

Values of $c, d$, and $d_{s}$ can be estimated by assuming that $c$ and $d$ are constant, whereas $d_{s}$ varies with wavelength. We estimated the value of $d_{s}$ for each of the functions in Figure 8 with $a$ set equal to 0.50 (as in Experiments 1-3 above) and with $c$ and $d$ constrained to take the same values for all functions. Thus, six free parameters were estimated from 23 data points. The fit yielded values of 1.00 and 0.0002 for $c$ and $d$, respectively; $d_{s}$ increased as an orderly monotonic function of wavelength difference, as is shown in the lower panel of Figure 8. In all, Equation 5 accounted for $94 \%$ of the variance. We conclude that our model can give an orderly account of stimulus generalization during EXT.

As was suggested above, Equation 5 predicts relatively greater generalization decrement for leaner schedules. This ordinal prediction holds for a wide range of parameter values as long as $a$ is greater than zero. Therefore, the slopes of relative generalization gradients are predicted to be steeper for leaner schedules. Although Walker and Branch (1998) obtained this result in their Experiment 2, they found little or no effect of reinforcer rate on gradient slopes in their Experiment 1, and the reverse result has been reported by Hearst, Koresko, and Poppen (1964). All of these studies involved training on single schedules where reinforcer rate varied between independent groups, rather than between components of a multiple schedule. Cohen, Riley, and Weigle (1993) have reported some conditions under which resistance to EXT was directly related to reinforcer rate in multiple schedules but was unrelated or inversely related to reinforcer rate after training on comparable single schedules. Therefore, the effects of reinforcer rate predicted by our model may be confirmed only when individual subjects are exposed to different reinforcer rates in fairly close temporal proximity, as in multiple schedules (cf. Cohen, 1998).

\section{Issues for Future Development}

As it stands, our model does not account for certain aspects of behavior during EXT. For example, free-operant EXT often shows an initial increase in response rate that is sometimes described as a frustrative effect of reinforcer omission, whereas our model predicts only decreases in responding. Also, it is reasonable to suppose that the effects of terminating the contingency and omitting reinforcers would change with time elapsed since the onset of EXT, whereas our model assumes constancy of the pa- rameters $c$ and $d$ with respect to sessions. Thus, Equation 5 is presented here as a good first approximation.

\section{Relations to Other Approaches}

Our approach to the role of reinforcer omission is closely related to that of Gibbon, Farrell, Locurto, Duncan, and Terrace (1980). They examined resistance to EXT after autoshaping, with reinforcer probability and the intertrial interval (ITI) varied between groups, and found that the rate at which responding declined during EXT was independent of the probability of reinforcement when their EXT data were plotted as functions of reinforcers omitted rather than of trials. Our Equation 5 becomes equivalent to the approach of Gibbon et al. if $c$ is 0 and $a$ is 1.0 so that the slope of the EXT curve is $d$, regardless of the probability of reinforcement. It is reasonable to set $c$ at 0 for the data of Gibbon et al., because they used an autoshaping procedure with no responsereinforcer contingency. Gibbon et al. reported that the slopes tended to become shallower as the ITI increased, and it may be that the scaled effect of omitting reinforcers is attenuated by long ITIs.

Our approach is also related to Staddon's (1975) account of resistance to EXT in relation to reinforcer rate. Briefly, he proposed that response strength (identified with response rate, not resistance to change) is a monotonic increasing, negatively accelerated function of reinforcer rate, whereas the contribution of reinforcers, as stimuli, to response strength is a linear increasing function of reinforcer rate. The contribution of reinforcers, as stimuli, is subtracted during EXT because they no longer occur. The remaining response strength is an inverted Ushaped function of reinforcer rate. Likewise, our Equation 5 assumes that response strength (identified with resistance to change) is a power function of reinforcer rate, which is negatively accelerated for $a<1.0$, and effectively treats the omission of reinforcement as a subtractive term (i.e., $d \Delta r$ is multiplied by $-x$ ). Moreover, when $r$ is varied up to high rates, Equation 5 predicts an inverted U-shaped relation between resistance to EXT and reinforcer rate (Nevin \& Grace, 2000a). In addition, our interpretation of reinforcer omission as generalization decrement accords with Staddon's account.

\section{Summary and Conclusion}

The key assumptions of our model are that response strength, measured as resistance to change, is an increasing function of the rate or amount of reinforcement and that resistance to EXT involves separate terms for terminating the operant contingency and omitting reinforcers, where the latter is interpreted as generalization decrement. Three multiple-schedule experiments support the identification of the model's key parameters with terminating the contingency and with generalization decrement, and the data are consistent with independence and additivity of those terms. The values of the parameters were reasonably consistent across experiments. The data of all three experiments are quantitatively consistent 
with a single value for the exponent of the power function relating response strength (construed as mass in the metaphor of behavioral momentum, Equation 1) to reinforcer rate.

The model was initially proposed by Nevin and Grace (1999) to account for the influence of the local context of reinforcement on resistance to EXT in schedule components with the same reinforcer rate. Nevin and Grace (2000a) showed that it could account for the widely reported finding that resistance to EXT is greater after intermittent than after continuous reinforcement, and it may be extended to encompass a wide range of variables that affect resistance to EXT. With the interpretation of its terms guided by future developments, the model may also be able to account for resistance to contingency changes other than termination and for schedule changes other than EXT.

\section{REFERENCES}

Catania, A. C. (1973). The nature of learning. In J. A. Nevin \& G. S. Reynolds (Eds.), The study of behavior (pp. 30-68). Glenview, IL: Scott, Foresman.

Catania, A. C., \& Keller, K. J. (1981). Contingency, contiguity, correlation, and the concept of causation. In P. Harzem \& M. D. Zeiler (Eds.), Predictability, correlation, and contiguity (pp. 125-167). Chichester, U.K.: Wiley.

Clark, F. C. (1959). Some quantitative properties of operant extinction data. Psychological Reports, 5, 131-139.

Cohen, S. L. (1998). Behavioral momentum: The effects of temporal separation of rates of reinforcement. Journal of the Experimental Analysis of Behavior, 69, 29-47.

Cohen, S. L., Riley, D. S., \& Weigle, P. A. (1993). Tests of behavior momentum in simple and multiple schedules with rats and pigeons. Journal of the Experimental Analysis of Behavior, 60, 255-291.

Gibbon, J., Farrell, L., Locurto, C. M., Duncan, H. J., \& Terrace, H. S. (1980). Partial reinforcement in autoshaping with pigeons. Animal Learning \& Behavior, 8, 45-59.

Grace, R. C., \& Nevin, J. A. (1997). On the relation between preference and resistance to change. Journal of the Experimental Analysis of Behavior, 67, 43-65.

Guttman, N., \& Kalish, H. I. (1956). Discriminability and stimulus generalization. Journal of Experimental Psychology, 51, 79-88.

HARPER, D. N., \& MCLeAn, A. P. (1992). Resistance to change and the law of effect. Journal of the Experimental Analysis of Behavior, 57, 317-337.
Hearst, E., Koresko, M. B., \& Poppen, R. (1964). Stimulus generalization and the response-reinforcer contingency. Journal of the Experimental Analysis of Behavior, 7, 369-380.

Hull, C. L. (1943). Principles of behavior. New York: AppletonCentury-Crofts.

IsAAC, P. D. (1970). Linear regression, structural relations, and measurement error. Psychological Bulletin, 74, 213-218.

LATTAL, K. A. (1972). Response-reinforcer independence and conventional extinction after fixed-interval and variable-interval schedules. Journal of the Experimental Analysis of Behavior, 18, 133-140.

Mackintosh, N. J. (1974). The psychology of animal learning. London: Academic Press.

Nevin, J. A. (1979). Reinforcement schedules and response strength. In M. D. Zeiler \& P. Harzem (Eds.), Reinforcement and the organization of behaviour (pp. 117-158). Chichester, U.K.: Wiley.

Nevin, J. A. (1992). An integrative model for the study of behavioral momentum. Journal of the Experimental Analysis of Behavior, 57, 301-316.

Nevin, J. A., \& Grace, R. C. (1999). Does resistance to change depend on the context of reinforcement? Journal of Experimental Psychology: Animal Behavior Processes, 25, 256-268.

Nevin, J. A., \& Grace, R. C. (2000a). Behavioral momentum and the law of effect. Behavioral \& Brain Sciences, 23, 73-130.

Nevin, J. A., \& Grace, R. C. (2000b). Preference and resistance to change with constant-duration schedule components. Journal of the Experimental Analysis of Behavior, 74, 79-100.

Nevin, J. A., Mandell, C., \& Atak, J. R. (1983). The analysis of behavioral momentum. Journal of the Experimental Analysis of Behavior, 39, 49-59.

Nevin, J. A., Mandell, C., \& Yarensky, P. (1981). Response rate and resistance to change in chained schedules. Journal of Experimental Psychology: Animal Behavior Processes, 7, 278-294.

RESCORLA, R. A., \& SKUCY, J. C. (1969). Effect of response-independent reinforcers during extinction. Journal of Comparative \& Physiological Psychology, 67, 381-389.

ReYNolDS, G. S. (1963). Some limitations on contrast and induction during successive discrimination. Journal of the Experimental Analysis of Behavior, 6, 131-139.

Shettleworth, S., \& Nevin, J. A. (1965). Relative rate of responding and relative magnitude of reinforcement in multiple schedules. Journal of the Experimental Analysis of Behavior, 8, 199-202.

STADDON, J. E. R. (1975). Learning as adaptation. In W. K. Estes (Ed.), Handbook of learning and cognitive processes: Vol. 2. Conditioning and behavior theory (pp. 37-98). Hillsdale, NJ: Erlbaum.

WALKER, D. J., \& BRANCH, M. N. (1998). Effects of variable-interval value and amount of training on stimulus generalization. Journal of the Experimental Analysis of Behavior, 70, 139-163.

(Manuscript received May 5, 1999;

revision accepted for publication October 30, 2000.) 